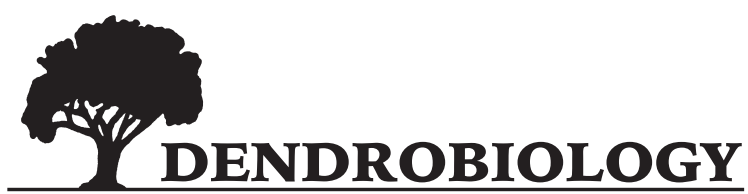 \\ 2013, vol. $69,21-30$
}

\author{
Elżbieta Myśkow, Beata Zagórska-Marek
}

\section{Dynamics of the ray pattern in cambium of Diospyros lotus}

Received: 5 March 2012; Accepted 3 July 2012

\begin{abstract}
Cambial rays, give rise to phloem and xylem rays. This way they affect the efficiency of a radial conducting system in a tree. Both, frequency of rays and their arrangement on the expanding cambial surface must be precisely controlled during tree ontogeny. The main aim of this research was to analyse the changes in the ray arrangement of Diospyros lotus L. cambium during transition from its nonstoried to double-storied structure. In order to trace the history of cambial ray dynamics, the behaviour of wood rays was followed in successive annual rings. Special attention was paid to developmental events, such as initiation and elimination of rays as well as their splitting and uniting. Moreover, the additions and eliminations of ray cell initials at the both opposite ray margins were followed. The most evident was the initial split of high primary rays into the smaller parts and their subsequent separation concurrent with the increase in cambial girth during the first years of a tree ontogeny. Between the existing rays new secondary rays were initiated by segmentation of fusiform initials. These all developmental events led to the formation of a double-storied pattern. In addition, the recurrent uniting and splitting of rays indicated their permanent rearrangement and the dynamic maintenance of a general pattern. The presented data are discussed in light of the processes occurring in cambial rays that lead to the storied pattern formation, which in turn may affect the mechanical properties of the wood.
\end{abstract}

Additional key words: cambial rays, double-storied cambium, ray development, ray initiation

Address: E. Myśkow, B. Zagórska-Marek, Institute of Experimental Biology, University of Wrocław, Kanonia 6/8, 50-328 Wrocław, Poland, e-mail: myskow@biol.uni.wroc.pl

\section{Introduction}

Secondary growth is a characteristic feature of shrubs and trees, which are widespread plant forms belonging to the different, phylogenetically unrelated plant groups (Groover 2005). Secondary thickening of plant axial organs results from the activity of the special lateral meristem - cambium, which gives rise to the secondary conductive tissues, namely internal xylem and external phloem (Larson 1994; Lachaud et al. 1999; Evert 2006).

Cambium consists of two types of initials: axially elongated fusiform initials and nearly isodiametric on tangential sections, but slightly elongated in radial direction ray cell initials gathered in groups, called ray initials or rays. These two types of initials divide periclinally (parallel to the stem surface) producing both an axial and radial conductive systems, perpendicular to each other in the secondary phloem and xylem (Bailey 1923; Bannan 1934; Larson 1994; Lachaud et al. 1999; Evert 2006).

Coincident with the tree growth in thickness, the diameter of cambium increases due to formation of new fusiform initials by anticlinal divisions followed by an intrusive and symplastic growth (Bailey 1923; Evert 1961; Cumbie 1967, 1984; Larson 1994). With 
cambial expansion, the existing, primary rays (rays originated at the outer margins of the primary tissues; Barghoorn 1940b) get separated circumferentially. Between them new secondary rays, i.e. the rays formed during secondary growth, are initiated (Barghoorn 1940b). Secondary rays arise from fusiform initials in various ways: 1 . by cutting off the small cell on the side or at the apical or basal tip of the fusiform initial; 2 . by reduction of the height of fusiform initial into a single ray initial; and 3 . by segmentation of the entire fusiform initial or of its fragment only by numerous transverse divisions (Bannan 1934; Barghoorn 1940a, b; Evert 1961; Cumbie 1967, 1984; Philipson et al. 1971; Butterfield 1972; Ghouse and Yunus 1973). During further cambial development, primary and secondary rays undergo modification of their height and width. Additions and eliminations of single ray cell initials at the both ray margins, as well as ray uniting and splitting of rays are the events, which modulate ray height (Bannan 1934; Barghoorn 1940a, b; Evert 1961; Ghouse and Yunus 1973; Larson 1994). Longitudinal anticlinal divisions of the ray cell initials located in the centre of the ray modulate in turn the ray's width and seriation (Barghoorn 1941; Evert 1961; Cumbie 1967; Ghouse and Yunus 1973; Larson 1994). Sometimes, the entire ray is eliminated from the cambial zone (Barghoorn 1940b; Zagórska-Marek 1977; Larson 1994; Myśkow and Zagórska-Marek 2004, 2008).

Referring to the arrangement of fusiform initials in the longitudinal tangential sections, Bailey (1923) described two types of cambial morphology: nonstoried cambium with irregular arrangement of initials, and storied cambium with initials of comparable lengths aligned in horizontal tiers - storeys. In storied cambium, besides fusiform initials, also the rays can be arranged in apparent storeys, forming a peculiar double-storied pattern (Romberger et al. 1993). The very high rays can form their own storeys, which are higher than those of fusiform initials, as in case of Sterculia tragacantha (Lawton 1972) but more often, the rays are small and enclosed within the fusiform initial storeys as in Dalbergia sissoo (Ghouse and Yunus 1973), Entandrophragma cylindricum (Hejnowicz and Zagórska-Marek 1974; Zagórska-Marek 1977) and Hippophaë rhamnoides (Myśkow and Zagórska-Marek 2004).

The regular double-storied pattern is also a characteristic feature of Diospyros lotus L. (Ebenaceae), and appears quickly - after three years of cambium activity (Myśkow 2010). Additionally, it has been shown that in $D$. lotus the rays are formed in early stage of ontogeny of the vascular meristem. The primordial ray initials has already been present during differentiation of primary conductive tissues, giving rise to extremely high although nonstoried primary rays in cambium (Myśkow 2010). Quite rapid transition from nonstoried to the storied ray pattern requires the rearrangement of primary and secondary ray layout. This in turn, may be achieved only by intensification of developmental events occurring in rays. The main aim of this research was to follow these events in cambium by reconstructing the history of changes in arrangement of both types of rays (primary and secondary) recorded in wood to learn more about the mechanisms governing the formation of storied pattern in ray arrangement in $D$. lotus cambium.

\section{Materials and methods}

Since developmental changes occurring in the arrangement of cambial cells are preserved in successive layers of secondary xylem, the history of cambial events can be reconstructed from the consecutive tangential sections of wood (Bailey 1923; Hejnowicz and Krawczyszyn 1969). The arrangement of fusiform initials is usually recorded once a year, in terminal parenchyma formed at the end of vegetative season, while arrangement of rays can be continuously observed throughout annual rings of wood (Hejnowicz and Krawczyszyn 1969).

To analyse the changes occurring in Diospyros lotus cambial rays, the wood block $(2 \mathrm{~cm} \times 2,5 \mathrm{~cm} \times 11,5$ $\mathrm{cm}$; tangential $\times$ longitudinal $\times$ radial dimensions) excised from the trunk of 40-year-old tree, fallen in the Botanical Garden of the University of Wrocław, was used. To soften the very hard wood of $D$. lotus the block was boiled in water with glycerol for 10 days (5-6 hours per day) and left for 4 months in a mixture of ethanol and glycerol (3:1). Subsequently, a developmental series of tangential sections (35 $\mu$ m thick each) was cut using a sliding microtome Leica S14 2000R (Leica Instruments, GmbH, Germany). Sections were attached to the glass slides with Haupt's adhesive, deaerated by alternative immersion in boiling and cold absolute alcohol (three times for $15 \mathrm{~min}$ ) and then embedded in Euparal (protocols after: Hejnowicz and Krawczyszyn 1969; Krawczyszyn 1973; Hejnowicz and Zagórska-Marek 1974; Włoch and Szendera 1992; Kojs et al. 2004; Myśkow and Zagórska-Marek 2004, 2008; Myśkow 2010).

To compare the cellular events occurring in cambial rays and changes in their arrangement, two groups containing different rays were randomly selected in the first tangential section near the pith. Both groups were separated one from another by the distance of $5 \mathrm{~mm}$ on the cambial surface. Then the chosen groups of rays were identified on every seventh section in successive annual rings, in developmental sequence from pith to cambium and photographed with use of the Olympus BX50 Microscope cooperating with Olympus Camera DP71 and Cell B Software (Olympus Optical Co., Warsaw, Poland). In that way, the arrangement of rays in each group was 
documented for further analyses as a series of digital images, consequently, the corresponding Series I and II present developmental events in each of ray groups. To assure accuracy in quantification of the events taking place in the same cambial area recorded in wood the successive images were aligned according to the position of one marker ray, positioned in a centre of each photograph. The size of the area occupied by the rays: $0,8 \mathrm{~mm} \times 0,5 \mathrm{~mm}$, was constant - the same on every successive photograph in both of the two (I and II) series. Then, the developmental events such as initiation and elimination of rays, their splitting and uniting as well as additions and eliminations of ray cell initials at the both opposite ray margins were traced. The uniting and splitting of rays may occur in two spatial (chiral) configurations, i.e. to the right $(Z)$ or to the left (S) when looking at the cambium surface from the secondary phloem side (compare Hejnowicz 1964; Hejnowicz and Krawczyszyn 1969). For that reason, the type of the event-its $Z$ or S orientation was recorded.

The double-storied pattern became ultimately established in the end of the third year of cambial activity (Myśkow 2010). Therefore to analyse the type of events and their frequency, as well as to be sure that they were stabilised and comparable in all successive years, the development of rays was traced through the first twelve annual rings.

The digital images were processed with the Macromedia Fireworks MX2004.

\section{Results}

Initially, near the pith, in each series, $55-60$ primary rays were present in the analysed area of the cambial surface. But at the end of the $12^{\text {th }}$ annual ring only $12-15$ remained in the area as a result of cambial circumferential growth.

In the course of investigation, the arrangement of 72 primary rays, selected out of a total of 110 , were reconstructed. Initially, primary rays were uniseriate and extremely high, reaching even c. $3 \mathrm{~mm}$ (Fig. 1a). Then, during the increase of the stem diameter, the primary rays grew apart one from another. Their spatial separation was due to divisions and growth of fusiform initials located between them (data not shown). In the process of primary rays separation, between them new, secondary rays were initiated from fusiform initials (Figs. 1b and 2). The double-storied pattern of cambium became apparent, starting from the third year of cambium activity (Fig. 1b).

Arrangement of rays was extremely dynamic: while the new rays were initiated, other rays disappeared from the investigated area, making it impossible to trace all the rays selected on the first section for the whole period of twelve years. Instead of the total number of rays, the overall number of particular cellular events taking place in primary and secondary rays was determined for the investigated area of a constant size. The recorded events were as follows: the initiation and elimination of rays, their splitting and uniting (Table 1) as well as the addition and elimination of ray cell initials (Table 2 ).
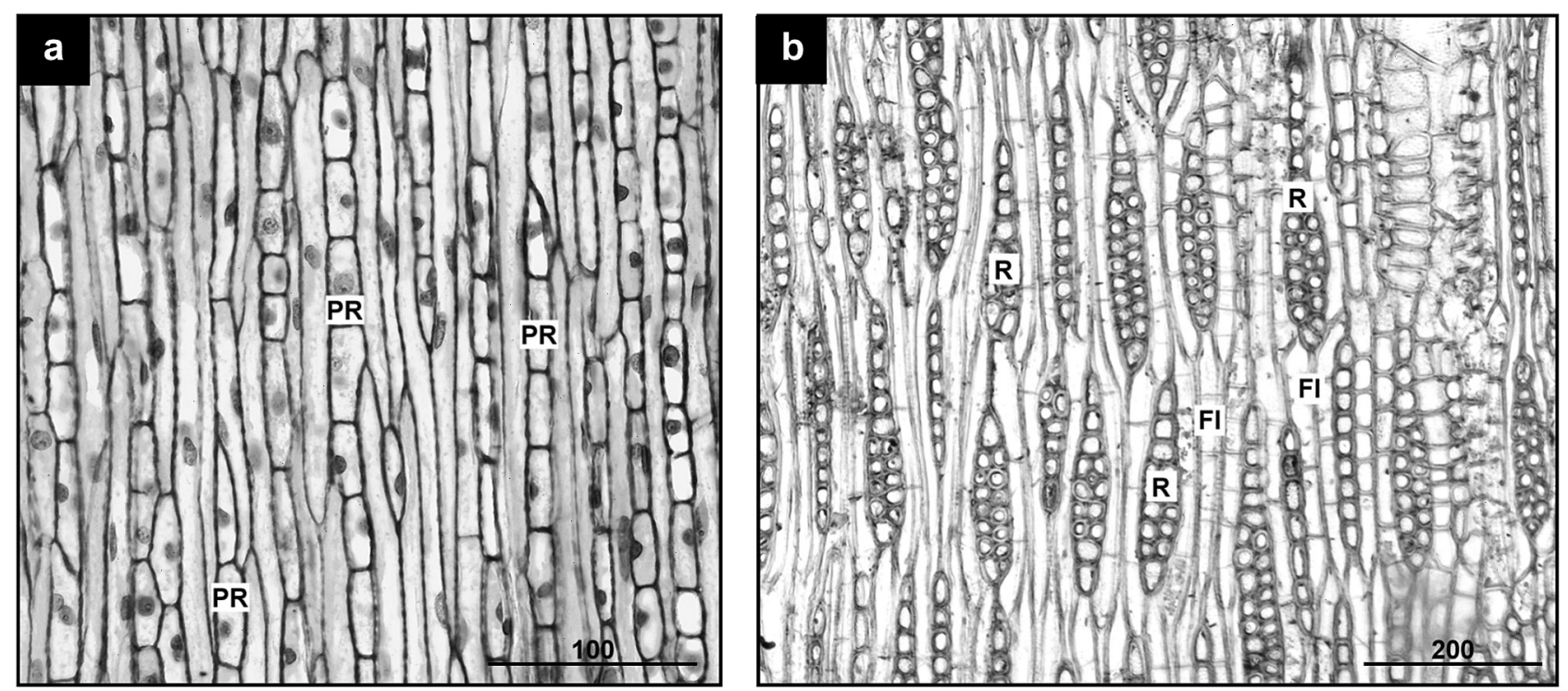

Fig. 1. The arrangement of rays in cambium of Diospyros lotus in one-year-old stem (a) and in the terminal layer of the $12^{\text {th }}$ annual ring (b) in tangential view. a - Initially all primary rays (PR) are very high and uniseriate. b - During further cambium development primary rays are split into smaller units, and become indistinguishable from secondary rays. Both, derivatives of fusiform initials (FI) and ray initials (R) are arrange in storeys forming double-storied cambium recorded in storied arrangement of terminal parenchyma cells and wood rays, respectively. Bars in $\mu \mathrm{m}$ 


\section{Initiation and development of secondary rays}

The initiation of secondary rays (203 new rays) was the most frequent event in D. lotus (Table 1).
From the total of 203 initiated rays, 191 were formed by segmentation of fusiform initials resulting from their serial transverse divisions (Table 2; Figs. 2a, b and Fig. 3). The first transverse division of the fusiform initial produced a new secondary ray, which
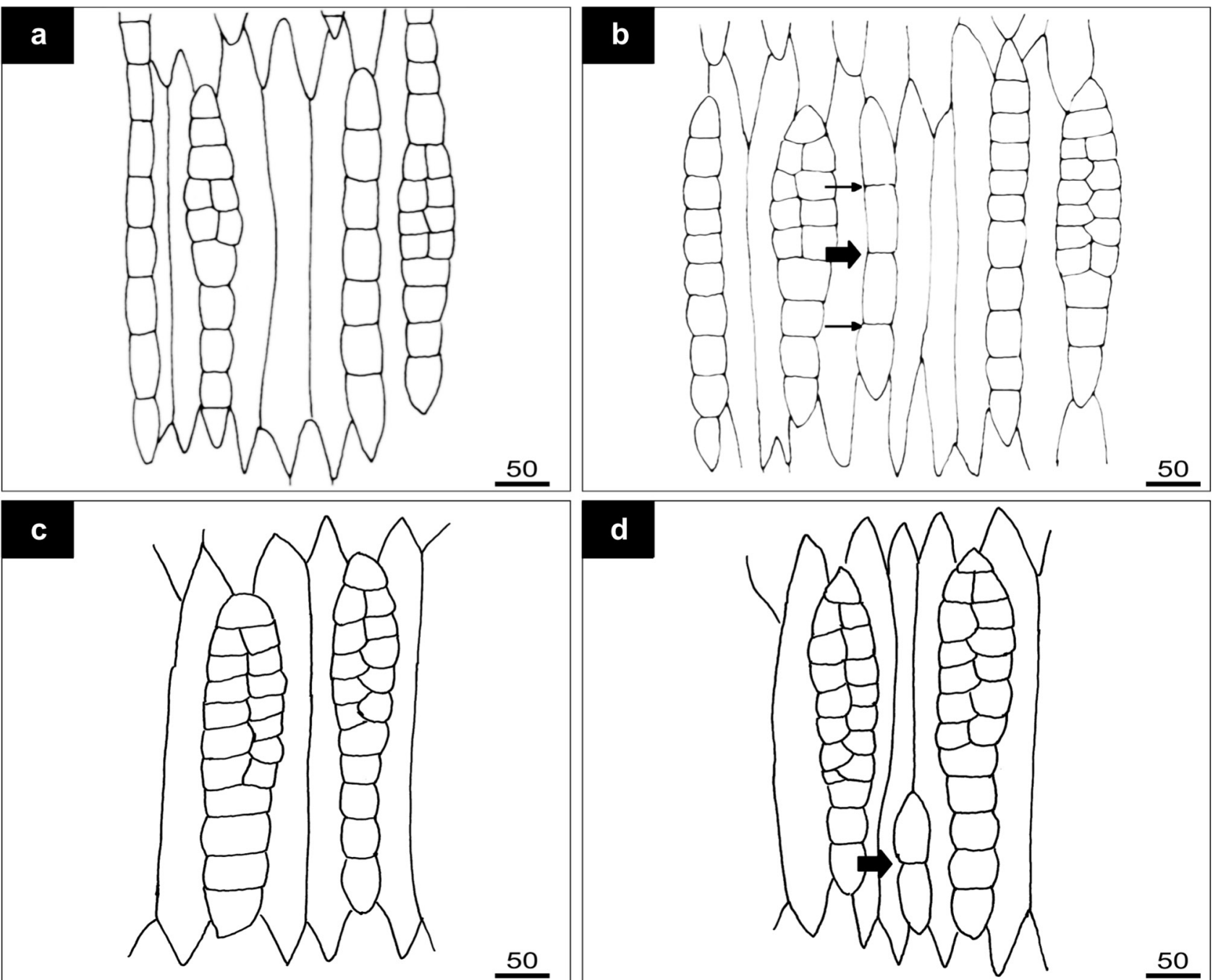

Fig. 2. Initiation of secondary rays in cambium, recorded in $D$. lotus wood. a, b and c, d - pairs of drawings of two consecutive terminal parenchyma layers showing initial arrangement of fusiform and ray initials (a, c), and initiation of a secondary ray $(b, d)$. a-b: ray initiation by segmentation of fusiform initial. The first transverse division (pointed by a block arrow) divides the fusiform initial into two axially elongated cells. Their consecutive divisions (small arrows) lead to increase in number of ray cell initials. c-d: initiation of ray by cut off of the basal margin of fusiform initial resulting in formation of one-cell-ray. Here, after ray initiation, the transverse division of ray cell initials took place in cambium before successive terminal parenchyma layer was deposited resulting in formation two-celled ray (pointed by a block arrow)

Table 1. The number of events occurring in cambial rays in Diospyros lotus. Two different groups of rays were chosen, followed, and photographed in consecutive tangential sections from the pith throughout the 12 annual rings of wood (Series I and II). During the cambium ontogeny the pattern of ray arrangement changed: between primary rays, new (secondary) rays were initiated. Splitting, uniting and elimination of rays occurred both in primary and secondary rays. All changes in ray arrangement, taking place during 12 years of cambium activity, were traced and classified

\begin{tabular}{lcccc}
\hline & Initiation of secondary rays & Ray splitting & Ray uniting & Ray elimination \\
\hline Series I & 108 & 84 & 58 & 6 \\
Series II & 95 & 70 & 50 & 7 \\
\hline Total number & 203 & 154 & 108 & 13 \\
\hline
\end{tabular}


Table 2. Number of transverse divisions and eliminations of cambial ray cell initials in Diospyros lotus cambium, according to localisation of the dividing cells. The changes were analysed in 160 secondary rays. Transverse division of cells on the apical or basal margin of the ray means that new ray cell initials are added at the ray margins. It is preceded by intrusive growth of marginal cells therefore the height of the entire ray increases. During consecutive cell divisions (segmentation) the ray height remains constant but single ray cell initials decrease in height. Ray cell initials located at the both margin of the ray (apical and basal) may be eliminated resulting in decreasing of ray height

\begin{tabular}{lcccc}
\hline & \multicolumn{2}{c}{ Number of transverse divisions } & \multicolumn{2}{c}{ Number of cell elimination } \\
\cline { 2 - 5 } & $\begin{array}{c}\text { cell at the apical } \\
\text { margin }\end{array}$ & $\begin{array}{c}\text { cell at the basal } \\
\text { margin }\end{array}$ & $\begin{array}{c}\text { central cell } \\
\text { (segmentation) }\end{array}$ & $\begin{array}{c}\text { cell at the apical } \\
\text { margin }\end{array}$ \\
\hline Series I & 120 & 98 & 253 & 46 \\
Series II & 105 & 98 & 271 & 40 \\
Total number & 225 & 196 & 524 & 28 \\
\hline
\end{tabular}

contained two axially elongated ray cell initials (Fig. $2 \mathrm{~b}$ and Fig. 3a). Occasionally, one of the two daughter cells quickly divided again, also transversely, and this led to formation of the ray three-cell-high (Fig. 3b). At this stage the height of the whole ray was rather stable. Further transverse divisions of axially elongated ray cell initials reduced their height increasing at the same time the cell number to six-eight per single ray. In 12 cases out of a total of 203, new secondary rays were initiated by cutting off the cell at the apical or basal tip of the fusiform initial (Figs. 2 c-d). In the next stage, during further development, regardless of the mode of initiation, new rays increased their height by addition of new ray cell initials at both margins of the ray (Fig. 3). The divisions of margin ray cell initials was possible because they are the only cells within the ray capable of elongation due to intrusive vertical growth.

During cambial development, the eliminations of ray cell initials (Figs. $4 \mathrm{~d}-\mathrm{e}$ ), decreasing the ray height, were also observed, but with low frequency (Table 2).

\section{Increase of primary and secondary ray seriation}

Initially, primary and secondary rays were uniseriate. During cambial development ray seriation increased by anticlinal longitudinal divisions of central ray cell initials (Fig. 3). The biseriate rays appeared in the first year of cambial development, and they comprised up to $37 \%$ of all the rays. In consecutive years, also tri- and tetraseriate rays appeared in cambium, however, after 12 years of cambial activity the uniseriate $(41 \%)$ and biseriate rays (33\%) still prevailed.

\section{Splitting, uniting and elimination of rays}

Primary and secondary rays are often split in cambium of $D$. lotus (Table 1). In the first year of cambial activity, splitting of rays occurred mainly in the high primary rays, leading to formation of groups of smaller daughter rays. Most of the primary rays split few times at the borders of the emerging storeys of fusiform initials, facilitating precise positioning of the daughter rays within the storeys of fusiform initials. Only eight primary rays did not split at the borders of storeys, extending in their height through two or three neighbouring storeys and disturbing the double-storied structure of cambium. During further cambial development, other high rays appeared in the effect of excessive addition of the ray cell initials or of the ray fusion. These were subsequently split into smaller rays. In $D$. lotus cambium the splitting of the ray was accomplished by intrusive growth of the adjacent fusiform initial, which in the most cases $(65 \%)$ was associated with an elimination of 1-3 ray cell initials at the site of ray division (Fig. 5). In all other cases $(35 \%)$, ray splitting occurred without elimination of ray cells. The process of ray splitting was always a chiral event; in Figure 5 the Z-type splitting is shown, because a lower ray after split is located to the right side of the upper ray; the opposite situation is denoted as S-type.

Alternately, rays, which increased in height by addition of the cells at the ray margins, and reached neighbouring storeys could unite with rays located there to form a high ray (Table 1). In the majority of cases (93 of 108) margins of such uniting rays may fused in different chiral configurations, i.e. either to the right (Z) or to the left (S) (data not shown). Only 12 pairs of uniting rays analysed, located one above another, fused without manifesting direction of the event, whereas in 3 cases, two laterally adjacent rays unite to form multiseriate ray (Fig. 6). In the studied ray population, $25 \%$ of ray uniting was preceded by their splitting as described above, indicating dynamic changes in ray arrangement.

The developmental analysis showed that during 12 years of $D$. lotus cambium activity only 13 rays were eliminated (Table 1). In seven cases the small ray, cut off by a ray splitting, was removed from cambium. In the remaining 6 events, the ray decreased in height by elimination of ray cell initials followed by the entire ray elimination from cambium (Fig. 4). 

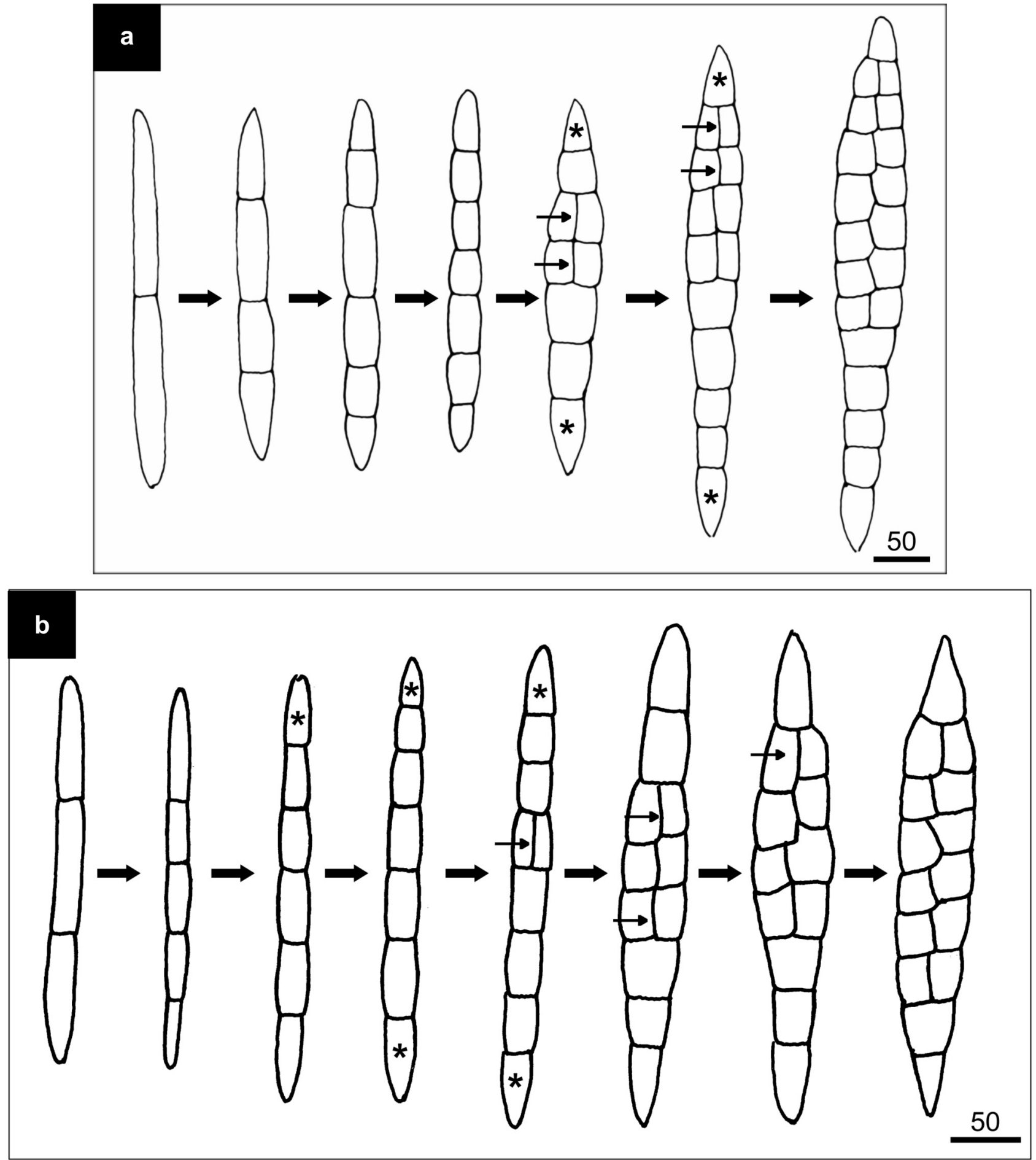

Fig. 3. Development of secondary rays in cambium, traced in $D$. lotus wood. New rays, originating by division of the fusiform initial, are initially composed of two (a) or three (b) vertically elongated initials. The increase in number of ray cell initials results from successive segmentations of these originally high ray cells. Then, the initial cells at the ray margins (denoted by stars) grow intrusively and divide transversely leading to addition of ray cell initials and increasing the ray height. Additionally, longitudinal divisions of ray cells, located in the centre of the ray (indicated by arrows), increase ray seriation. The thickness of xylem layer deposited between successive stages of ray development is equal to $9.7 \mathrm{~mm}$ in (a) and 13.2 $\mathrm{mm}$ in (b). Bar - in $\mu \mathrm{m}$ 


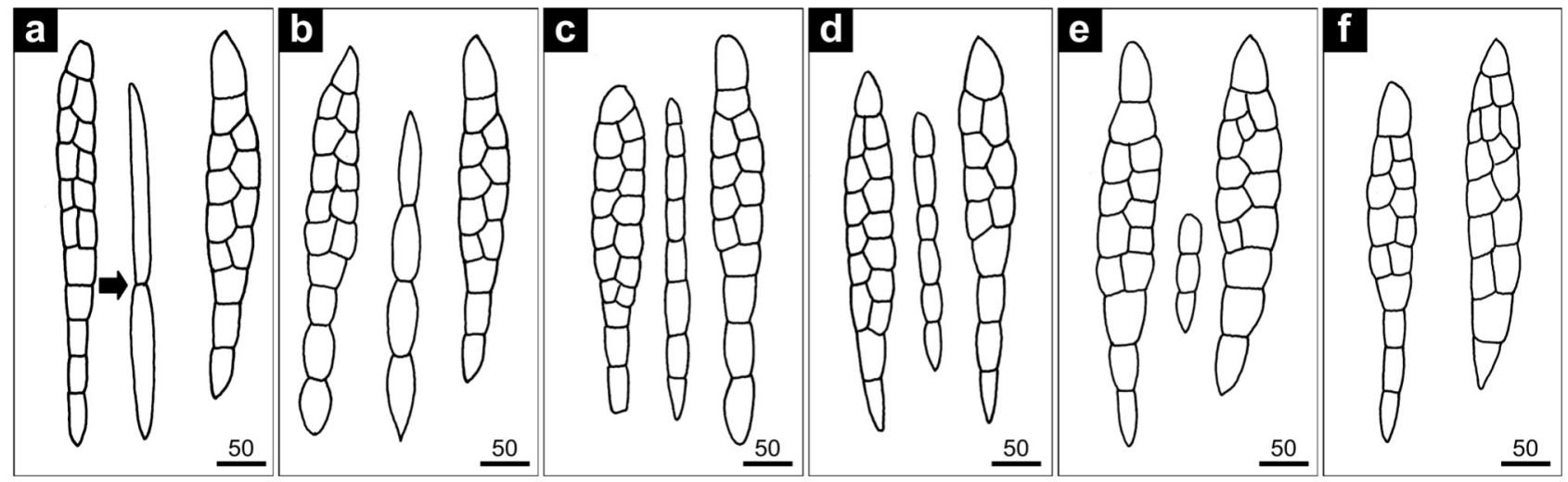

Fig. 4. The history of cambial ray recorded in secondary wood of D. lotus. a - initiation of two-celled-ray (indicated by an arrow) between older rays; b and c - following segmentation of the ray leading to formation of eight-celled-ray; $d$ - elimination of two ray cell initials at the ray margins reduces the ray height to six ray cell initials; $\mathrm{e}$ - further elimination of ray cell initials decreases the ray height to three cells and ultimately leads to complete elimination of ray from the cambium (f). The thickness of xylem layer deposited between stages (a) and (f) $-13.1 \mathrm{~mm}$. Bar- in $\mu \mathrm{m}$
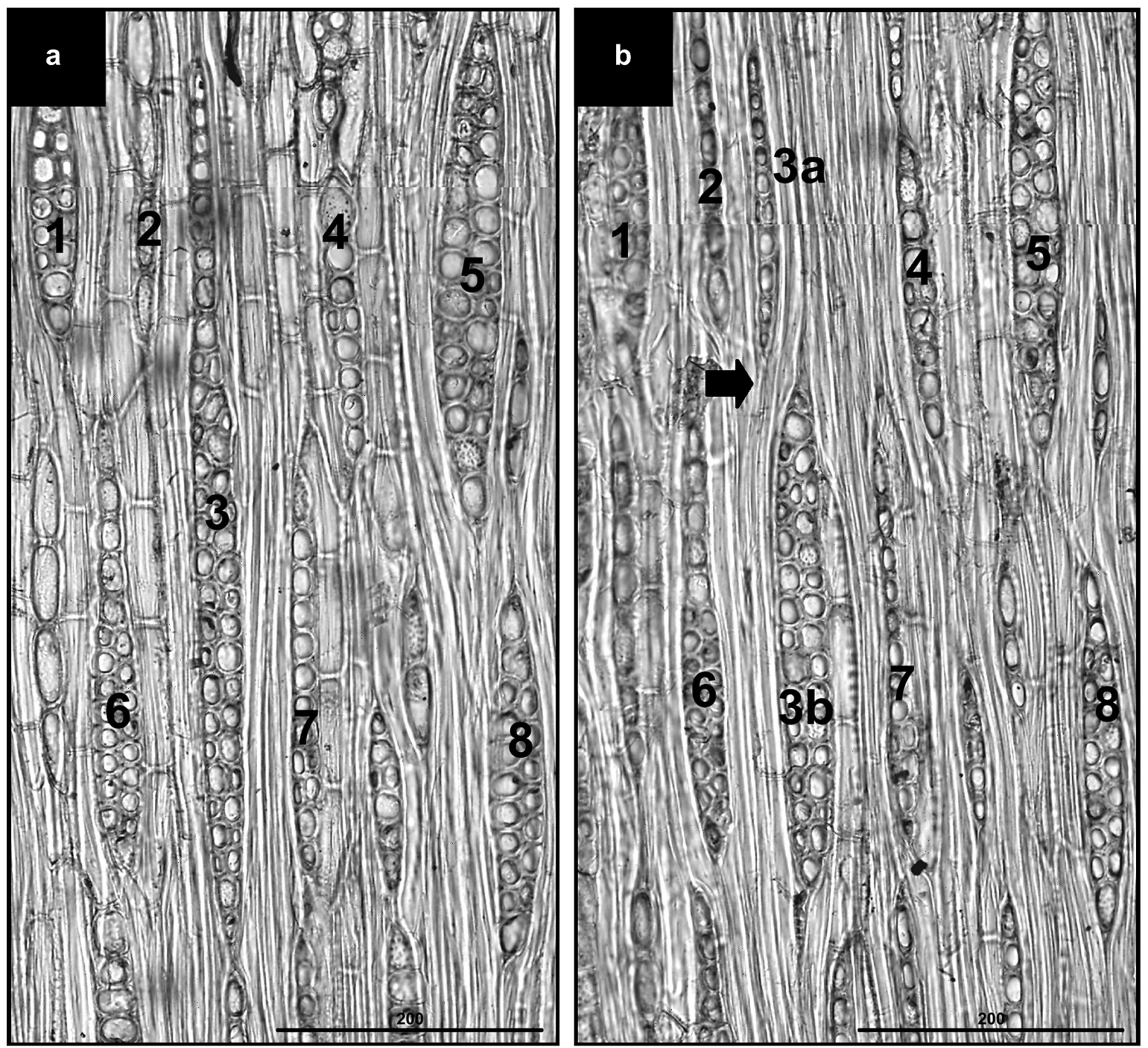

Fig. 5. Splitting of the high ray shown in D. lotus wood. a - initial arrangement of rays; b-very high ray No. 3 is split (indicated by a block arrow) at the border of two fusiform initial storeys into daughter rays No. 3a and 3b, by intrusive growth of the adjacent fusiform initial. The direction of splitting is of the Z-type. Some of ray cell initials, located in the site of split, are eliminated from cambium. The thickness of xylem layer deposited between stages (a) and (b) $-0.4 \mathrm{~mm}$. Bar- in $\mu \mathrm{m}$ 

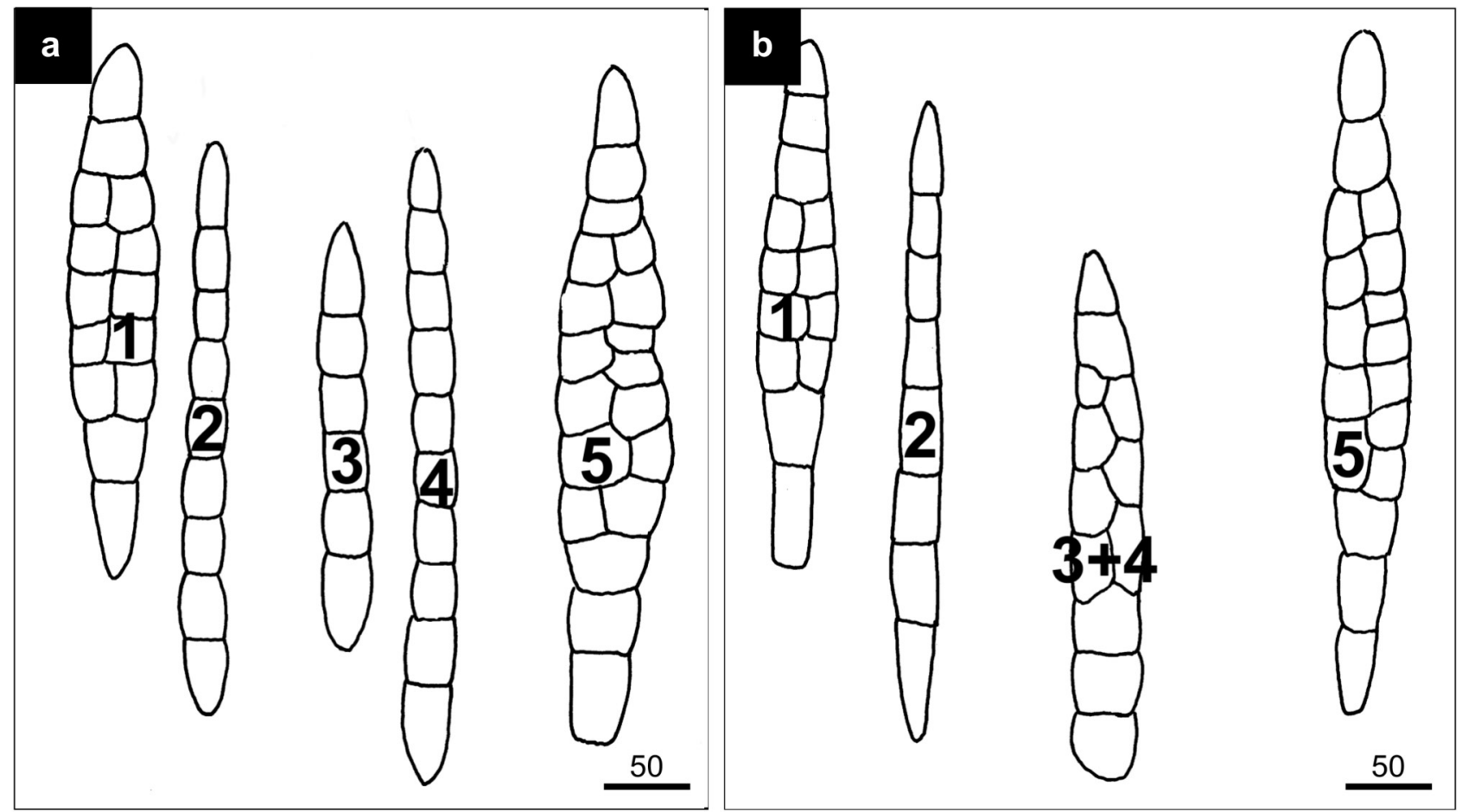

Fig. 6. Two successive stages of ray uniting in D. lotus cambium. Laterally adjacent uniseriate rays No. 3 and 4 (in a panel) unite to form the biseriate ray (No. 3+4; shown in b panel). The thickness of xylem layer deposited between stages shown in (a) and (b) $-0.7 \mathrm{~mm}$. Bar - in $\mu \mathrm{m}$

\section{Discussion}

Cambial rays generate the phloem and xylem rays which are essential for the translocation of the nutrients, hormones and messenger molecules (Lachaud et al. 1999). They also play a crucial role in starch and nitrogen accumulation during dormancy (Philipson et al. 1971; Höll 2000). Thus, the overall number of rays and their arrangement on cambial surface are species-specific, precisely controlled and regulated (Barghoorn 1940b, 1941; Bünning 1952; Philipson et al. 1971; Lachaud et al. 1999). While cambial circumference increases, new secondary rays must be initiated between existing cambial rays to maintain relatively constant ratio of fusiform and ray initials throughout the secondary growth (Bünning 1952; Evert 1961; Philipson et al. 1971). In this work we present the processes occurring in the cambial rays, which guarantee the maintenance of the proper ray number in cambium of Diospyros lotus during radial expansion of the tissue. We also show the mechanisms that regulate the arrangement of rays in a course of double-storied cambium growth.

Changes occurring in primary and secondary rays of $D$. lotus cambium were reconstructed from the record of developmental events stored in the wood rays pattern. Our data show that in the first years of cambial activity the changes in D. lotus cambium are related to the fast radial growth of the stem, which re- sults in growing apart and splitting of initially high primary rays. In many dicotyledonous plants, primary rays are extremely high and split into smaller units during cambial development (Barghoorn 1940b). Splitting of rays applies to both uniseriate and multiseriate primary rays (Cumbie 1967; Krawczyszyn 1973; Włoch and Szendera 1992; Myśkow and Zagórska-Marek 2004, 2008), however, smaller ray seriation, facilitate ray splitting (Włoch and Szendera 1989). The preferable site of ray splitting in D. lotus is the border of storeys of adjacent fusiform initials; as a consequence, the daughter rays are located precisely inside the existing storeys as in Tilia cordata (Włoch and Szendera 1989), Entandrophragma cylindricum (Hejnowicz and Zagórska-Marek 1974; Zagórska-Marek 1977) and Hippophaë rhamnoides (Myśkow and Zagórska-Marek 2004). New secondary rays are initiated in $D$. lotus, mostly by successive transverse divisions of vertically elongated fusiform initials (segmentation), in the manner known to other species (Butterfield 1972; Ghouse and Yunus 1973; Cumbie 1984; Myśkow and Zagórska-Marek 2004). Initiation of new rays assures the sufficient number of rays supplying stems, which increase in diameter during development.

Taking into account the developmental events occurring in D. lotus cambium it seems that the phylogenetically advanced storied arrangement of rays in cambium is achieved by splitting of extremely high 
primary rays by intrusively growing fusiform initials concurrently with initiation of secondary rays precisely within the fusiform initial storeys. A similar mechanism of formation of storied ray pattern was also observed in Hippophaë rhamnoides (Myśkow and Zagórska-Marek 2004). However, the double-storied pattern in D. lotus originates early in tree ontogeny already after three years of cambial activity, and is dynamically maintained in following years. Dynamics of the ray pattern is manifested by repeated splitting and uniting of the rays at the borders between fusiform initial storeys. High frequency of such events suggests that the arrangement of rays may be reshuffled in cambial ontogeny without disturbing the double-storied structure. A similar dynamic regulation of morphogenetic patterns was observed in cambium during formation and maintenance of storied arrangement of fusiform initials in Tilia cordata (Zagórska-Marek 1984) and Wisteria floribunda (Kojs et al. 2004). The rays may also dynamically change their location in cambium of Aesculus turbinata. In this species, vertical migration of rays leads to sorting them out into storeys (Myśkow and Zagórska-Marek 2008). It has been postulated that trees may benefit from the ordered cambium structure, which facilitates the intensive and synchronised reorientation of cambial cells, alternately to the right and to the left (Hejnowicz and Zagórska-Marek 1974). Recurrent events such as uniting and splitting would probably impede reorientation of cambial cells as in Tilia parvifolia (Hejnowicz and Zagórska-Marek 1974). Thus the ability to restore and maintain the double-storied structure keeps regular reorientations of cells possible and in turn leads to formation of the interlocked grain in wood (Hejnowicz and Zagórska-Marek 1974; Hejnowicz and Romberger 1979). Wood with interlocked grain originates when inclination of fusiform initials alters repeatedly in cambium, and these periodical oscillations are reflected in alternating inclination of secondary xylem elements, viewed along the radius in consecutive annual rings (Hejnowicz and Romberger 1979; Romberger et al. 1993). The interlocked structure increases wood mechanical properties (Kojs et al. 2003). Regarding that the double-storied cambium and interlocked wood grain are common features in tropical trees, intensively growing in height to get better light conditions, Kojs et al. (2003) postulated that both these features have an adaptive value, and enable trees to compete with other species in the tropics. High mechanical properties of Diospyros wood manifested by extremely hard and dense hardwood (Brown et al. 1949) result not only from the type of xylem elements differentiated but also from their arrangement guaranteed by the dynamic cambium structure.

\section{Acknowledgments}

We would like to thank all our colleagues from the Department of Developmental Plant Biology at the Institute of Experimental Biology for their helpful discussion and comments. This work has been supported by the Polish State Committee for Scientific Research (KBN), grant No. 3PO4C 08822.

\section{References}

Bailey I.W. 1923. The cambium and its derivative tissues. IV. The increase in girth of the cambium. American Journal of Botany 10: 499-509.

Bannan M.W. 1934. Origin and cellular character of xylem rays in gymnosperms. Botanical Gazette 96: 260-281.

Barghoorn E.S. Jr. 1940a. Origin and development of the uniseriate ray in the Coniferae. Bulletin of the Torrey Botanical Club 67: 303-328.

Barghoorn E.S. Jr. 1940b. The ontogenetic development and phylogenetic specialization of rays in the xylem of dicotyledons. I. The primitive ray structure. American Journal of Botany 27: 918-928.

Barghoorn E.S. Jr. 1941. The ontogenetic development and phylogenetic specialization of rays in the xylem of dicotyledons. II. Modification of the multiseriate and uniseriate rays. American Journal of Botany 28: 273-282.

Brown H.P., Panshin A.J., Forsaith C.C. 1949. Textbook of wood technology. Vol. I. Structure, identification, defects, and uses of the commercial woods of the United States. McGraw-Hill Book Company, Inc. New York, Toronto, London.

Butterfield B.G. 1972. Developmental changes in the vascular cambium of Aeschynomene hispida Willd. New Zealand Journal of Botany 10: 373-386.

Bünning E. 1952. Morphogenesis in plants. Survey of Biological Progress 2: 105-140.

Cumbie B.G. 1967. Development and structure of the xylem of Canavalia (Leguminosae). Bulletin of the Torrey Botanical Club 94: 162-175.

Cumbie B.G. 1984. Origin and development of the vascular cambium in Aeschynomene virginica. Bulletin of the Torrey Botanical Club 111: 42-50.

Evert R.F. 1961. Some aspects of cambial development in Pyrus communis. American Journal of Botany 48: 479-488.

Evert R.F. 2006. Esau's plant anatomy. Meristems, cells, and tissues of the plant body - their structure, function, and development. Third edition. Published by: John Wiley \& Sons. Inc., Hoboken. New Jersey. USA.

Ghouse A.K.M., Yunus M. 1973. Some aspects of cambial development in the shoots of Dalbergia sissoo Roxb. Flora 162: 549-558. 
Groover A.T. 2005. What genes make a tree a tree? Trends in Plant Science 10: 210-214.

Höll W. 2000. Distribution, fluctuation and metabolism of food reserves in the wood of trees. In: Cell and molecular biology of wood formation. Savidge R.A., Barnett J.R., Napier R. (eds.). London, UK: BIOS Scientific Publishers, pp. 347-362.

Hejnowicz Z. 1964. Orientation of the partition in pseudotransverse division in cambia of some conifers. Canadian Journal of Botany 42: 1685-1691.

Hejnowicz Z., Krawczyszyn J. 1969. Oriented morphogenetic phenomena in cambium of broadleaved trees. Acta Societatis Botanicorum Poloniae 38: 547-560.

Hejnowicz Z., Romberger J.A. 1979. The common basis of wood grain figures is the systematically changing orientation of cambial fusiform cells. Wood Science and Technology 13: 89-96.

Hejnowicz Z., Zagórska-Marek B. 1974. Mechanism of changes in grain inclination in wood produced by storeyed cambium. Acta Societatis Botanicorum Poloniae 43: 381-398.

Kojs P., Włoch W., Rusin A., Rusin T. 2003. Interlocked grain as an ecological advantage in large emergents and canopy trees. Proceedings of $1^{\text {st }}$ Conference of the Polish Society for Plant Experimental Biology. Polish Journal of Natural Sciences Supplement 1, p. 205

Kojs P., Rusin A., Iqbal M., Włoch W., Jura J., 2004. Readjustments of cambial initials in Wisteria floribunda (Willd.) DC. for development of storeyed structure. New Phytologist 163: 287-297.

Krawczyszyn J. 1973. Domain pattern in the cambium of young Platanus stems. Acta Societatis Botanicorum Poloniae 42: 637-648.

Lachaud S., Catesson A-M., Bonnemain J-L. 1999. Structure and functions of the vascular cambium. Comptes rendus de l'Académie des Sciences, III 322: 633-650.
Larson P.R. 1994. The vascular cambium. Development and structure. Springer-Verlag. Berlin, Heidelber, Germany.

Lawton J.R. 1972. Seasonal variations in the secondary phloem of some forest trees from Nigeria. II. Structure of the phloem. New Phytologist 71: 335-348.

Myśkow E. 2010. Procambium-cambium transition during vascular meristem development in Diospyros lotus. Botany 88: 985-993.

Myśkow E., Zagórska-Marek B. 2004. Ontogenetic development of storied ray pattern in cambium of Hippophä̈ rhamnoides L. Acta Societatis Botanicorum Poloniae 73: 93-101.

Myśkow E., Zagórska-Marek B. 2008. Vertical migration of rays leads to the development of a double-storied phenotype in the cambium of Aesculus turbinata. Botany 86: 36-44.

Philipson W.R., Ward J.M., Butterfield B.G. 1971. The vascular cambium. Its development and activity. Chapman \& Hall Ltd, London.

Romberger J.A., Hejnowicz Z., Hill J.F. 1993. Plant structure: function and development. A treatise on anatomy and vegetative development, with special reference to woody plants. Springer-Verlag. Berlin-Hidelberg-New York.

Włoch W., Szendera W. 1989. The storeyed and non-storeyed arrangement of rays in the storeyed cambium of Tilia cordata Mill. Acta Societatis Botanicorum Poloniae 58: 211-228.

Włoch W., Szendera W. 1992. Observation of changes of cambial domain patterns on the basis of primary ray development in Fagus silvatica L. Acta Societatis Botanicorum Poloniae 61: 319-330.

Zagórska-Marek B. 1977. Developmental events in storied cambium. PhD thesis, Institute of Botany. University of Wrocław, Wrocław, Poland (in Polish).

Zagórska-Marek B. 1984. Pseudotransverse divisions and intrusive elongation of fusiform initials in storeyed cambium of Tilia. Canadian Journal of Botany 62: 20-27. 